\title{
Behind Disaster Management: Resiliency in Cultural Configuration
}

\author{
Raj Kumar Bhattarai, PhD \\ Associate Professor \\ Nepal Commerce Campus, TU \\ raj@ncc.edu.np
}

\begin{abstract}
The paper discovers the worth of a resilient culture in the course of disaster management following 2015's Nepal Earthquake. An empirical investigation into the activities of rescues, rescuers, government authorities, humanitarian agencies, and civil societies indicates that the effectiveness of rescue, relief, recovery, and reconstruction activities are influenced by their cultural resiliency. The discovery process involved field visits, personal observation and experience, interviews, literature review and discourse analysis as well as interpretation. The study concentrated on the issues concerning the areas of rescue operations, logistics, information sharing, supply chains, shelter management, relief packages distribution, actors' coordination, and socio-cultural immunity and elasticity to the crisis conditions. This paper draws a conclusion that resilience in cultural configuration enhances effectiveness in the process of disaster management.
\end{abstract}

Keywords: Nepal Earthquake, Disaster Management, Cultural Configuration, Socio-cultural Immunity, Resilient Culture

\section{Introduction}

Disaster is a sudden event that causes huge damage and loss of lives. Such events occur either due to accidents or natural phenomena, and also lead to a humanitarian crisis in addition to the damage and loss of lives. Humanitarian crisis is a condition of severe hardships in the daily lives of the disaster survivors. Shortage and insecurity (Bhattarai, 2016) at one part and mental grief and physical pain at the other are fuelling the situation of survivors' hardships. The situation becomes very hard to overcome without resiliency in cultural configuration of the survivors and the rescuers. Enhancing resiliency in cultural configuration is a secret of disaster management. 


\section{Disaster Management}

This paper considers disaster management as a process of building resiliency through which the disaster survivors of disasters are better able to cope with their grief, pain and hardships so that they return to their normal lives. The process consists of emergency preparedness, response, recovery, and restructuring. Mental grief, physical pain, material loss and damage of structures are common phenomenon under disaster conditions. Such anxieties often lead the survivors to a state of powerlessness and isolation. Life of these survivors remains full of shortage, irregularity, and insecurity.

The preparedness process entails all assumptions and forecasts concerning the disaster and it makes the matter ready for early response thereon. At first, managing rescue operations, logistics, shelter, and relief materials are a few areas of concerns of all. A disaster dismantles socio-psychological settings of the survivors; therefore, the recovery process necessarily attempts to restore the routine life of the survivors.

Post disaster socio-psychological processes attempt to develop a new order that will be building a new socio-psychological order along with restructuring the socioinstitutional settings. Moreover, the disaster damages the physical structures or that eventually need rebuilding and restructuring.

\section{The Disaster: Nepal Earthquake}

The earthquake recorded 7.6 in magnitude and subsequent aftershocks caused a huge damage and loss of lives in Nepal (seeTable 1 Table below). The quake struck on $25^{\text {th }}$ day of April 2015 at 11:56 AM local time with an epicenter at the Gorkha district of Nepalnorthwest of Kathmandu. The following days' aftershocks-mainly the aftershock of 6.7 in magnitude recorded on the $26^{\text {th }}$ day of April 2015 and the aftershock of 6.8 in magnitude recorded on the $12^{\text {th }}$ day of May 2015-also caused additional damage and loss of lives (quantified below). Mainly, the quake caused severe damage in 14 districts (Bhaktapur Dhading; Dolakha; Gorkha; Kathmandu; Kavrepalanchowk; Lalitpur; Makawanpur; Nuwakot; Okhaldhunga; Ramechhap; Rasuwa; Sindhuli; and Sindhupalchowk) and it caused tolerable damages in other 31 districts of Nepal.

The earthquake and subsequent aftershocks did not only cause physical losses and damages, but it also affected the survivors in a number of socio-psychological and cultural aspects. The grief, pain and hardships of the survivors are still continuous in their makeshifts even after three years of the disaster. Their ways of lives consisting the events and festivals, rituals and customs, livelihoods and styles of living among others are not returning back to their original position in most of the cases. A high level of tolerance and compromise among the survivors found praiseworthy. 
Table 1

Loss and Damage

\begin{tabular}{|c|c|c|}
\hline Description & Unit & Quantity \\
\hline Death & person & 8,970 \\
\hline Injured & person & 22,302 \\
\hline Missing & person & 198 \\
\hline Fully damaged houses & number & 604,930 \\
\hline Partially damaged houses & number & 288,856 \\
\hline Total value of disaster effects & Billion Rs. & 706 \\
\hline Proportion of physical assets destroyed & percent & 76 \\
\hline Proportion of other losses & percent & 24 \\
\hline Affected families & number & 886,456 \\
\hline
\end{tabular}

Source: Ministry of Home Affairs; Nepal Police; National Society for Earthquake Technology The Issues and Challenges

Disaster preparedness practices in Nepal couldn't enhance resiliency amongst the people and societies. The current system still concentrates on rescue and relief operations. Domestic strength of responding to disasters independently is deteriorating from the overwhelming dependency on outsiders the donors and philanthropists.

Diversified nature of the donors and philanthropists is thwarting the integration and coordination attempts of disaster preparedness and response. It is obvious that when pluralistic nature and preference exist among the principal actors, the local requirements disappear in the entire process of disaster management. Eventually, the preparedness and responding practices of the donors and philanthropists undermine the preference and priority of the rescues and the survivors.

Immunity to change of principal actors including the government, donors, philanthropists, local organizations and people appears as a challenge during the period of disaster response and recovery. Disaster condition is discontinuation of the past and beginning for continuation of the future. It is the condition of change; therefore, both immunity and adaptability are essential. However, people and institutions are lacking such immunity and adaptability. They rely on their own pattern of getting things done and they attempt to exercise accordingly throughout the disaster management process.

Integrity and commitment of political parties and government agencies are essential to mobilize resources efficiently and effectively in the process. Administrative support, community mobilization, and transparency in operations are crucial parts in response, 
recovery and reconstruction phases of disaster management. Higher the integrity and commitment of the actors, faster the processes of disaster management.

The management of humanitarian logistics is immediate concern of disaster management. For instance, the rescuers need logistic supports for their rescue operation at one part and the rescues need water, foods, shelters, sanitation and security at the other part. The disaster is affecting the supply chain and its actors adversely by damaging physical infrastructures like roads and bridges, houses and warehouses, markets and business complex among others.

A favorable weather condition facilitates the disaster management process in a number of ways. More specifically, the summers and winters are more challenging due to the heavy rainfalls in summers and excessive cold in the winters. The earthquakes damage homes and make the survivors compelled to adjust with makeshift, which are not all seasons weatherproof. Humanitarian operations logistics, recovery measures, and reconstruction activities become efficient and effective in fair weather conditions.

Security measures of person and property help ensure confidence and instill hope among the survivors. Community supports and cooperation will be increased, and disaster management process will be enhanced. The actors including donors and philanthropists also feel confidence in their operations. Trust among the actors will be enhanced and plans will be materialized.

Accuracy in information and communication minimizes the negative impacts of rumor that is spreading across the disaster areas. Rumor perception varies from person to person and society to society. Nepal consists of rumor prone societies where people quickly believe on rumors and tend to respond accordingly.

\section{Statement of the Problem}

Earthquake breaks physical settings. The breaking of physical, socio-cultural settings, totally or partially, causes loss of lives and affects lives-patterns of the habitats. The earthquake survivors' rehabilitation of an earthquake's survivors is the primary concern of the disaster management.

a. Which dimensions of the survivors' live-patterns does earthquake-caused loss and damage affect the most?

b. What becomes instrumental to ensure effective rehabilitation of those who survived the earthquake-caused disasters?

\section{Methodology}

This is exploratory narrative research. It consisted of disaster site visits, interviews with opinion leaders, discourse analysis and literature review concerning humanitarian operations logistics and disaster management. The site visits covered all the headquarters and nearby areas of 14 affected districts. The interviews of opinion leaders involved Nepal police (2), Nepal army (2), Nepal government's district offices (14), international 
non-governmental organization (7), national non-governmental organization (13), major political parties (4), individuals involved in humanitarian works (5) and the earthquake victims (47); the number is parenthesis refers the number of respondents.

Out of 94 respondents, only 20 respondents were comfortable for recording their interviews and remaining 74 were comfortable only for making notes. From among the 74 respondents, 15 respondents didn't permit to disclose their names. Out of the 15 respondents, 13 were from Nepal government's district offices and two from the victims. The interviews and responses were transliterated for exploratory narratives.

The narratives, site observations and literature reviews helped to develop discourses on beliefs, attitudes, and value preferences of the survivors, politicians, government officers, and humanitarian actors. Analysis of the discourse developed as such was used to ensure the significance of cultural configuration (Bhattarai, 2016) in restoring the livepatterns of the survivors and its likely instrumentality for their rehabilitation.

This study focuses on priority and practice of identifying and restoring the disaster survivors' daily lives. Review of literature in brief provided insights in understanding the role and category of the actors involved as well as humanitarian operations logistics. The review indicated a few areas of concern and priority while managing disasters. Humanitarian context, information diffusion, evacuation and transportation, supply chain, shelter management, relief material distribution, actor coordination, and socio-cultural immunity to crisis, and resilient culture were considered major influencers.

\section{Limitation}

This study depends on personal observation and experience as well as on the discourse analysis based on field observations, interviews, and literature review. Activities and impact thereof of the actors like local community, humanitarians, political activists, government officers, and security forces were not assessed in the study. The discourse was indicating a substantial amount of activities for preparedness; however, the study did not explore the relationship between the preparedness and loss/damage. The study put higher emphasis on humanitarian operations logistics.

\section{Literature Review}

Humanitarian function manifests the humanistic values and devotion. A humanitarian, a person or an institution is devoted to the protection and promotion of human welfare. It is an advocate of the principles of humanism that has concerns about the interests and welfare of human beings. Humanitarian operations consist of a set of functions intended to avail human welfare in every circumstance. It is an enduring process of ensuring humanistic values and principles, which are desirable, compatible and comfortable for people. Humanitarian operations logistics involves the process of providing and handling labor and materials in order to safeguard human lives, values and principles over times and situations. 
United Nations Cluster Approach to humanitarian emergencies consists of seven clusters-prevention, mitigation, preparedness, disaster, response, recovery and reconstruction-organized into eleven thematic areas- emergency shelter; nutrition; logistics; sanitation, water and hygiene; education; early recovery; emergency telecommunications; food security; protection; health; and camp coordination and management (UNOCHA, 2005). Bhimani and Song (2016) divide humanitarian logistics into four research streams - mitigation, preparedness, response and recovery - and research needs into two practices-disaster response and capacity building.

Vanajakumari, Kumar and Gupta (2016) focus on the streams of integrated/ coordinated decision models, last mile distribution problem, facility location problem, and vehicle management problem and propose an integrated optimization model for simultaneously determining locations of staging areas, inventory assignments, selecting sizes and numbers of trucks, and routing of trucks.

This study divides the literature on humanitarian logistics and disaster management process in eight streams concerning the humanitarian context, information diffusion, evacuees' evacuation, shelter management, supply chains, relief packages, actors' coordination, and socio-cultural immunity to crisis.

\section{Humanitarian Context}

Humanitarian operations are unique in nature. The operations seem socially responsive, philanthropically attractive and profitably distractive. Disaster or crisis conditions consist of contextual complexities. Humanitarian operations rely heavily on logistics in uncertain, risky, and urgent contexts-a very different field of application for supply chain management principles than that of ordinary businesses (Gatignon, Wassenhove, \& Charles, 2010)

Pluralistic interests of humanitarian actors - social responsibility, philanthropy and profitability are fueling the complexities. Complexity, unfamiliar context and intuitive behavior of socially responsive operations are inviting challenges for making decisions. In some cases, humanitarian operations involve local governments or people, who are important stakeholders as well as beneficiaries of the operations. Socially responsive operations are complex set in an unfamiliar context involving uncertainty and multiple stakeholders with conflicting goals and can lead to counter-intuitive behavior (Besiou \& Wassenhove, 2015).

The context to humanitarian operations logistics vary significantly according to the policies of the principal actors like the government, local and international organizations. For instance, vehicle procurement policy for humanitarian development programs has been considered significant in few sensitive countries like Sudan, Afghanistan, and Ethiopia (Eftekhar, Masini, Robotis, \& Wassenhove, 2014). The context in least developed countries consists of a large number of poor people-both the recipient and the distributors. Management research needs to explore the impact of engaging the poor people as 
suppliers or distributers (Sodhi \& Tang, 2014) in humanitarian operations logistics.

\section{Information Diffusion}

Role of information diffusion is pivotal during disasters. The information processing view of the UN's cluster approach provides an avenue for information diffusion. The clusters, if properly utilized, encourage better information flow and thus facilitate effective response to disasters. Humanitarian attention needs to turn to the importance of sharing information in order to facilitate humanitarian aid from elsewhere. Information quality is critical for effective resource utilization. Information quality, willingness to exchange information, and role of cluster lead as information hub have a larger role in information diffusion for effective response during disaster (Altay \& Pal, 2014). Humanitarian logistics models and their solutions need to be integrated with information technology to enable their use in practice (Ozdamar \& Ertem, 2014).

\section{Supply Chain}

Efficacy of different asset transfer mechanisms for the design of humanitarian supply chains is essential; however, humanitarian programs typically operate under funding constraints and donor earmarks with autonomous decision-making authority resting with the local entities, which makes the design of efficient humanitarian supply chain a challenging problem (Bhattacharya, Hasija, \& Wassenhove, 2014). Trust is essential to supply chain actors, which needs a significantly long-term association among the actors. Hastily formed networks on the spot-in absence of the actors' relationships of a long term-will have a limited application (Tatham \& Kocacs, 2009) in humanitarian logistics. The use of social enterprises to buttress the supply chains for distribution of essential goods by coordinating with micro-retailers is also considered useful in strengthening supply chain before and after the disaster (Sodhi \& Tang, 2014)

\section{Evacuation and Transportation}

Moving people from the location of disasters/calamities to the location of shelters encounters multiple challenges. Locating shelter sites, determining routes, preparing evacuees, managing traffic, and minimizing evacuation time are few possible challenges. The number and locations of shelter sites and the trade-off between efficiency and fairness are essential considerations (Bayram, Tansel, \& Yaman, 2014) in the process of evacuation. The task of transporting evacuees to shelter area involves multiple challenges, including vehicle management. Mobilization of vehicles incurs substantial financial costs. Humanitarian organizations like the International Committee of the Red Cross can make a considerable amount of savings by adjusting their vehicle replacement policy (Pedraza-Martinez \& Wassenhove, 2013). Transportation of evacuees and supplies is one of the most important functions in the process of humanitarian logistics. The costs associated with transportation have been considered the second largest overhead cost to humanitarian organizations after personnel costs (Martinez, Stapleton, \& Wassenhove, 2011). 


\section{Shelter Management}

The donors often exhibit their preference for humanitarian programs (Besiou, Pedraza-Martinez, \& Wassenhove, 2014) related to evacuation and shelter management. Selection of shelter sites for the evacuees needs to follow methodology and mathematical model to ensure effectiveness in the relief operations-when the threshold distances to health institutions and main roads decreases, the objective value also decreases (Kilci, Kara, \& Bozkaya, 2014). Shelter management requires substantial amount of varied resources. In order to ensure continuous flow of resources, a central entity that can acquire primary resources and sell them to the other programs can improve system efficiency (Bhattacharya, Hasija, \& Wassenhove, 2014).

\section{Relief Package Distribution}

The nature and types of humanitarian relief programs vary significantly depending on the humanitarian context, disasters, or crisis. As an instance, school feeding programs had a substantial impact in many less-developed countries when those programs were run by international organizations; however, World Food Program prompted a shift towards long-term, sustainable solutions that rely more on local resources, local capacity, and community participation (Kretschmer, Spinler, \& Wassenhove, 2014). Humanitarian logistics help in making relief programs effective. The logistics have challenges of allocating scarce resources to complex operations in effective ways (Wassenhove \& Martinez, 2012).

\section{Actors' Coordination}

A large number and variety of actors are engaged in the process of humanitarian operations logistics with different mission, interests, capacity, and logistics expertise. Coordination among the actors involved in humanitarian operations is obviously essential, as it is essential among the commercial actors. The commercial supply chain management has been well studied within the domain of coordination mechanism (Balcik, Beamon, Krejci, Muramatsu, \& Ramirez, 2009). Commercial operations mechanism and humanitarian operation mechanisms are fundamentally different in terms of their intended purpose. The intended purpose of commercial operation is to make profit whereas intended purpose of humanitarian operation is to avail relief to the victims, specifically during disasters or calamities.

Pluralistic interests of the actors in humanitarian operations do not necessarily encourage coordination. The number and diversity of actors, donor expectations and funding structure, resource shortages or surpluses, and unpredictability are making the coordination efforts harder and dearer. Relief chain coordination primarily depends on the efficiency and effectiveness of the chain structure, supply acquisition, warehousing, transportation and distribution of relief materials and services. The coordination mechanisms involve the mechanisms of national and international relief actors and philanthropists as well as the mechanisms of commercial actors (Balcik, Beamon, Krejci, Muramatsu, \& Ramirez, 2009).

Journal of Business and Social Sciences (JBSS) 
Socio-cultural Immunity to Crisis

Humanitarian operations logistics effectiveness largely depends on the sociocultural immunity to crisis. Cultural configuration (Bhattarai, 2015) of the people providers and recipients of the logistics-determines the effectiveness of humanitarian logistics and disaster management process. Socio-cultural immunity emerges along with the advancement of empathy, cooperation and trust among the actors. The trust, both interpersonal and inter-organizational, has been argued to have positive consequences for the success of a relationship, even reducing transaction costs (Tatham \& Kocacs, 2009).

The immunity to crisis does not only refer to the ability of resistance and tolerance during disasters but also refers to the post-disaster humanitarian welfare in the affected society. Large disasters and catastrophes can imperil or destroy the conditions of buyers and sellers to conduct economic transactions. The social costs composed of logistic and deprivation costs (Holguin-Veras, Perez, Jaller, Wassenhove, \& Aros-Vera, 2013) are further escalating the crisis if there is vulnerable socio-cultural immunity to crisis. Potential consequences of disasters, for an instance, involve overwhelming economic losses, largely affected populations and serious environmental damages (Galindo \& Batta, 2013).

\section{The Critic}

The attempts of disaster preparedness, humanitarian operations logistics and post-disaster management practices did not address the significance of cultural configuration and its impact on the live-patterns of the survivors. The history of success in using modeling and analysis in emergency planning and responsiveness demonstrates that management science can and should play an important role in minimizing the impact of both routine and catastrophic emergencies (Green \& Kolesar, 2004). However, humanitarian logistics is too broad a field to fit neatly into a single definition of operational conditions (Holguin-Veras, Jaller, Wassenhove, Perez, \& Wachtendorf, 2012). The context of humanitarian catastrophes does not follow a particular process. Uniqueness of the humanitarian context, information diffusion, supply chain, evacuation and transportation, shelter management, pluralistic actors' coordination, relief programs, cultural resiliency and socio-immunity are making the humanitarian operations logistics and disaster management process different across the societies, more specifically, in poor countries.

Disasters and calamities are damaging societies in an interval of unspecified times. Effectiveness in the function of humanitarian logistics is the primary concern of all the actors in their operations. The existing literature on humanitarian logistics concentrates broadly on the areas of information diffusion, evacuation and transportation, supply chains, shelter management, relief package distribution, and actors' coordination. The literature remains absent, more specifically, on the cultural configuration, socio-cultural complexity, rumors handling, actors' value concerns and their relationships, personnel mobilization, culture and value (in) compatibility of the rescues, ethical concerns and adoptive challenges. 


\section{Discussion}

Infrastructure and material advancement commensurate to the patterns of lives in a society. Live-patterns of individuals are reflecting the cultural configuration in a social setting. A congruence of physical structure and cultural configuration is making lives comfortable, compatible and sustainable in societies. The disasters like earthquakes are not only breaking the physical structures and causing loss of lives, but also challenging the comfortability, compatibility and sustainability of the socio-cultural lives. The loss and damage are influencing the live-patterns of individuals and societies significantly; therefore, one of the secrets of earthquake-like disaster management is building a resilient culture.

\section{Disaster Management Process}

An analysis of discourse indicates a practice of categorizing disaster management process into three categories; preparedness, response and recovery. The category of preparedness consisted of preventive measures, which involved the tasks of identifying disaster prone areas, determining space for shelter, developing the shelter areas, and awareness building for likely disasters. Urban areas, such as Kathmandu Valley, were identified as disaster-prone areas and hence more vulnerable, amongst others. Rural areas, mainly the areas outside Kathmandu valley, were not getting attention. The activities of identification and development of shelter areas were not effective as there was no single shelter area that had been developed even in Kathmandu valley. The tasks of infrastructure development, institutional setups, rescue operations, relief package determination and rehabilitation measure were negligible. However, the tasks of awareness building were getting their own momentum.

Insufficient preparedness invited a large number of obstacles in response to the earthquake. The process of information dissemination could not be effective enough due to heavy traffic and connectivity loss. Personal benefit seeking tendency of the principal actors and ineffective information dissemination caused difficulties and delays in locating real rescues. The quake damaged rural areas were more severe and vulnerable when compared with urban areas; however, the rescuers were concentrated more on urban and accessible areas. Ineffective communication and absence of transportation facilities including the capacity of airports caused imbalances in distribution of rescuers and relief materials. Inefficiency and ineffectiveness in response increased chaos in communities at one part and self-response and self-mobilization became the only one alternative for the survivors at the other part. Nevertheless, the efforts of Nepalese police and military forces remain exemplary in the rescue operations. The social immunity to disaster adversaries encouraged community mobilization and local participation during the rescue operations. Foreign rescuers' efforts were also encouraging.

The endeavors of recovery and reconstruction could not get pace as expected due to a number of reasons. There were delays in formulation of reconstruction policy and reconstruction authority. Fundamental question like who should take the charge of recovery and reconstruction remained unanswered for months. During the months, the 
government was not taking in-charge of it itself; moreover, private and public sectors including non-government organizations and humanitarians were not allowed to take the charge of it.

Excessive dependency on others; international donors, philanthropists, and the governments were also causing for delays in the process of recovery and reconstruction. Communities were waiting for cash and kind from the government irrespective of their sole capability of recovery and reconstruction. Almost everyone was waiting and watching the government or the outsiders for relief and recovery.

Personal contacts and affiliation helped most in every aspects of the disaster. Rescuers and relief materials were reaching first to those locations from where any type of lead or personal contact was available. Those locations and people were only waiting for the relief materials and supports which had no one to get contact with the government, donors, humanitarians and rescuers. However, collectivism was encouraged, and individualism was discouraged in local participation.

Post-earthquake facilitation and support assurance from the donors and foreigners were substantial and inspirational. However, insufficient attention of the disaster management program of the nation and absence of supportive laws, rules and regulations, the supports and assurance of outsiders couldn't be materialized. Eventually, the survivors were spending their lives in makeshifts for whole year and even more than year in case of some survivors.

\section{Cultural Configuration}

The notion of resiliency incorporates the immunity and elasticity of conformance to the philosophy and live-patterns of individuals in a society. An individual's philosophy of live is embedded in its own cultural configuration; the pattern of action, reaction and interaction. When disasters, such as a powerful earthquake take place, then an individual's live-patterns start being affected in multiple ways. Damage of physical structures, loss of lives, injuries, irregularities, fear and insecurities are obvious among the affected people. It abruptly brings changes and if the changes are compatible and comfortable to the individual's cultural configuration, then that individual's cultural immune system welcomes it, otherwise it attempts to discard and starts fighting against the changes.

Resiliency has two dimensions- surviving lives from difficulties, and prospering lives from opportunities. The humanitarian operations; logistics, rescue, recovery, reconstructions are ultimately directed to restore the live-patterns of the survivors. How quickly and confidently people come back to their own normal live-patterns that determine the effectiveness of resiliency. Entire efforts of disaster management process become ineffective if the immune system is fighting against the efforts of disaster management. A resilient culture enhances the level of tolerance for ambiguities and hardships at one part and prepares ready to be adaptive to the changing situation that is emerging from the disaster at the other. 
Cultural configuration is a web of enduring choices and requirements in due course of lives. Bhattarai (2016) determines a web of seven elements that form an individual's cultural whole. The daily lives of the survivors become very difficult when the disaster management process ignore their cultural configuration.

This study found a comparison effect among the survivors. The survivors tend to relate the government's firmness in helping and keeping them secured, supports from the humanitarian agencies, their requirements and possessions so far to their own context and circumstances. They may make comparison of their case with the case of similar other knowns-in their own locality or outside of it. When they find their case better than others' case, then their progression towards resiliency will be quicker, instead, if the case is worst, than the others, then they may lose their resilient capability during the period of crisis and disasters. The following elements of a culture were found fundamental matters of conformance and comparison.

\section{Surviving and Sheltering (बचाउनु तथा बसाउनु)}

One of the priorities in disaster management process is to ensure the survival of people and/or to make sure that the survivors are eating, wearing, sleeping and getting sufficient care. Somewhere, the patterns of eating and sheltering vary according to gender, age, health condition, geographic location, situation, religion and ethnicity. Drinking water, sanitation facilities, health cares, clothing, security, fuel and energy are some basic items need to be available for the rescues. This dimension of disaster management does not only concern to the rescue operations, but it is also concerned to the preparedness and recovery/reconstruction stages. Identification of disaster-prone areas, locating shelter sites, and developing response mechanisms are some major concerns at the stage of preparedness. The shelter management is an instrumental aspect of disaster management for establishing and promoting a resilient culture in disaster area.

\section{Valuing and Working (मुल्य-मान्यता तथा कार्य ब्यवस्था)}

Multiplicity in value preference or vested interests of the parties and their own working modalities create obstacles in disaster management process. Value congruence between the providers and recipients only helps to make the management process more effective. The laws, rules, regulations, ethical standards, empathy, priorities, profession and vocation of the providers and recipients are significant parts of this dimension of a culture. The works related to preparedness, rescue, recovery and reconstruction needs to be specified for each involved, more specifically for the beneficiaries that the disaster management activities are in congruence with their value preference. An effective disaster management ensures that the survivors will be quickly returning to their normal working lives. The disaster management process needs to facilitate the survivors so that they can engage into their works in any way. Working modalities of the governments, humanitarian agencies and donors need to be flexible depending on the context. Motive of valuing work than valuing worth and working for social benefits not for personal benefit only works best during disasters. 


\section{Events and Festivals (चाडपर्व)}

This is celebrating part of a culture, which consists of a variety of events and festivals concerning the people survived in the disaster area. Survivors need to celebrate different events and festivals in order to get some reliefs from the pain of the disaster. The disaster condition is putting the survivors into grief, pain and hardships. They are unable to get materials, money, space, and people for celebration. Events and festivals are taking place at their own; therefore, provision of celebration in post-disaster condition facilitates the survivors to bring them back to their normal life in their own society.

\section{Etiquette and Manner (शिष्टाचार)}

Mannering dimension of a disaster management process is concerned to specific parts of an individual's behavior that is serving as an instrument while dealing with others. It refers the formal rules of correct or polite behavior in society or among the members of a particular profession. Choice of attire, gestures and postures, interaction patterns, seating arrangements, meeting people and visiting places are some of the examples of etiquette and manner. Compatible etiquette and manner between the rescues and rescuers, government officials and survivors are instrumental in the disaster management process. Incompatible manner and etiquettes accelerate unnecessary psychological and emotional pressures during the disaster management process.

\section{Rituals and Tradition (संस्कार तथा परम्परा)}

Ritualizing aspect in disaster management is concerned with the convention, social norms and practices that are reflecting in a series of actions. The actions are mostly carried out in the same way over time especially as part of a cultural ceremony. The rituals vary from religion to religion and communities to communities. Some rituals and traditions are contradictory as well i.e. acceptable in one religion or community is unacceptable in other religion or community. For example, a Hindus worship cows, considering them as a sacred animal, whereas other religions suck as Islam and Christianity believe otherwise. Cremation and last rites of the deceased persons, relief materials selection and distribution, events and festivals celebration, working patterns, and regular rituals like marriage and anniversaries are drawing attention of the survivors.

\section{Timing and Scheduling (मुहूर्त तथा समय सारणी)}

Timing dimension of disaster management process is concerned with the significance given by the parties in relation to their schedule and datelines. The parties are entering into a number of agreements that are essential in all the stages of disaster management. Any one party of the agreement fails to meet its own schedule and dateline then there is difficulty for other parties to meet their schedule and datelines. Punctuality is one of the most reliable indicators of timing preference of the parties in the disaster management process. Every second is important to save life and to secure property. Delay in response and reconstruction is not only increases the damage and loss but it is also fueling for frustration among the survivors. 


\section{Learning and Wisdom (सिकाइ तथा बुध्दमित्ता)}

Disaster condition is the condition of change in which discontinuation of the past is obvious. The conditions of damaged infrastructure, loss of lives, articles of trade shortage, security lapses and chaos in the societies are demanding unique response. The concerns like how people learn the ways of surviving and sheltering depends on the learning and wisdom of the actors involved in the disaster management. Best design and superior experience require modification as well. Physical, psychological and emotional controls of every individual at one part and controls over the resources, rumors and responses at the other part become possible only from learning and wisdom of the disaster management actors.

A resilient cultural configuration promotes an organic approach to disaster management instead of traditional and mechanical approach. Accuracy in projection and identification of beneficiaries is strictly maintained and its access is expanded beyond the accessibility and approachability. Resilient culture gives more emphasis on community feedback mechanism and perception of the survivors. Responding quickly for rescue and recovery at one part and converting disaster into opportunities at other part are major attractions of a resilient culture.

Capacity development at individual and community level for disaster management is essential to enhance a resilient culture.

The culture ensures rehabilitation package strictly based on real needs, opinions and suggestions of the beneficiaries rather than the interests and priorities of the outsiders - the donors and humanitarian agencies. Establishment and operationalization of an independent and fully authorized agency to respond to the complaints and irregularities in the process of disaster management is necessary. Separation of power based on ownership and responsibility of the decisions and actions at local level requires for transparency in decisions and actions of every concerned actors and beneficiaries. Regular attempt of advancing information and communication promotes compatibility among the elements of a resilient culture.

\section{Inference}

This study draws subjective inference on the assessment of disaster management practice in relation to the earthquake and subsequent aftershocks. There were substantial efforts paid for preparedness and response, but very limited efforts were made for recovery and reconstruction thereof. More than necessary dependency on outsiders of the local community in disaster areas in addition to the infrastructural, financial and administrative obstacles was one of the impediments in the process of disaster management.

\section{Geography, Infrastructure and Weather}

Typical terrain, absence of infrastructure and remoteness of the disaster areas itself were causing problems concerning information, communication, and transportation. If any infrastructures and facilities were already developed in the areas that were damaged 
by the earthquake. Monsoon was fueling to the obstacles to distribute the relief materials.

\section{Supply Chain Management and Embargo}

Commodities shortage was obvious to the disaster areas in absence of supply chain. Embargo at Nepal-India border escalated the shortages and damaged the supply chain, mainly the transporters of commodity. Ineffective management of supply chain, there was loss of products in the transits substantial portion of relief materials were diverted to commercial sectors before reaching to the disaster areas.

\section{Perception}

Respondents to this study perceived that personal benefit seeking attitude and corrupt behavior of some influential government officers was a major drawback, with consensus on the notion that most politicians were in it for their own gain. Politicians bargained with the humanitarian aid distributors, tempting such organizations to support the distributors; in case of any kind of failure to meet their demands, the politicians would create obstacles in humanitarian activities conducted by such organizations. Perception of the survivors about the politicians and government officers was like that the humanitarian agencies were providing personal benefits to the politicians and officers and only the politicians and government officers were appreciating the agencies; in case of not providing such benefits, both the politicians and the officers were not only criticizing the humanitarian agencies' efforts but also, they were creating obstacles to the agencies. Similarly, perception of government officers and politicians was that of resources shortage, poor infrastructure, absence of coordination, superiority of donors and humanitarian agencies, violation of government rules and regulations, and undermining their roles in the process of disaster management.

\section{Reconstruction Authority}

There was a delay in the formulation of a reconstruction policy and the establishment of a reconstruction authority thereof. Almost after eight months since of the earthquake, the government came with policies for reconstruction. At the beginning of the disaster, there was a confusion on who should be allowed for reconstruction works-the government itself, international non-governmental organization (INGO), or any other organization(s). Later, a reconstruction authority was established to take charge of the reconstruction works. Even after policy formulation and the establishment of a reconstruction authority establishment, there was not much effectiveness in implementing the policy and expediting the works of reconstruction.

\section{Working Patterns of Humanitarians}

Very few humanitarian and aid agencies were reaching remote areas that were badly affected by the disaster. People who were living in inaccessible areas were not getting benefits of those agencies. Most of the agencies were active in accessible areas: areas with roadways or airways connection. The relief workers were not reaching to inaccessible areas because they were not interested to walk hours by foot to reach to the victims. This tendency deprived the victims from getting relief materials at rural areas; instead, the 
agencies only reached to accessible areas to distribute their materials. Eventually, the survivors at rural areas could not get these benefits, but the survivors at accessible areas received multifold of the benefits.

\section{District Disaster Relief Committee (DDRC)}

Under the chairmanship of chief district officer, DDRC was formed in which local development officer was serving as a secretary to the committee. However, there was a perceptual charge that inappropriate and unwanted behavior of such government officers was making the efforts of relief distribution less effective.

\section{Need Assessment}

There was absence of communication with local people/beneficiaries to identify their real need and requirement to recover from the disaster. What beneficiaries wanted to receive was not important but what the humanitarian agencies wanted to give was important. Somewhere, the relief materials provided from the humanitarians at their own discretion were of no use at all for the survivors. In case of few humanitarian agencies, need assessment and relief materials distribution were based on political affiliation of its executives. Executives were biased to their affiliated party workers, and benefits were going to their party workers or supporters first. Only the workers or supporters were getting the relief materials, and if there was access of such materials, they were selling it to the market but not giving or selling to the victims of other party workers or supporters.

\section{Business Practice Reporting}

The government could not manage the customs and checkpoints during the disaster period. Business minded people were importing commodities in the name of relief materials, and they were diverting the commodity to their own warehouses for commercial purpose. Such people were bribing the law enforcing personnel to divert the products as well. In some cases, humanitarians were facing administrative delays and difficulties at custom points as well. There was no transparent record keeping and accounting practice of relief materials entered into the country during the period. Black-marketing was taking place but reporting of unethical business practices was absent or ineffective.

\section{Conclusion}

More centralized capacity development practices and unnecessary involvement of aid agencies in the name of development resulted an increased dependency of individuals and communities on the government and outsiders. Disaster management process confined to safeguarding and restructuring the structural settings. The process ignored the significance of socio-cultural settings and resiliency thereof. The notions of recovery and rehabilitation are inherently human, but the notion of physical reconstruction is shadowing the significance of cultural configuration. The principle of "survivors" choice first' could not get importance and the notion of survivors' comfortability could not be materialized as expected. Moreover, personal-benefit-seeking tendency of the authorities and frontline individuals derailed the humanitarian operations logistics and rehabilitation processes, if any. Principal actors' tendency of undermining the significance of cultural 
resiliency and socio-economic immunity could not help to achieve expected efficiency and effectiveness in the process of disaster management in Nepal.

\section{References}

Altay, N., \& Pal, R. 2014: Information diffusion among agents: Implications for humanitarian operations. Production and Operations Management, 23(6), pp 1015-1027.

Balcik, B., Beamon, B. M., Krejci, C. C., Muramatsu, K. M., \& Ramirez, M. 2009: Coordination in humanitarian relief chains: Practices, challentes and opportunities. Int. J. Production Economics, 126(2010), pp22-34.

Bayram, V., Tansel, B. C., \& Yaman, H. 2014: Compromising system and user interests in shelter location and evacuation planning. Transportation Research Part B, 72(2015), pp146-163.

Besiou, M., \& Wassenhove, L. N. 2015: Addressing the challenge of modeling for decisionmaking in socially responsible operations. Production and Operations Management, 24(9), pp1390-1401.

Besiou, M., Pedraza-Martinez, A. J., \& Wassenhove, L. N. 2014: Vehicle supply chains in humanitarian operations: decentralization, operational mix, and earmarked funding. Production and Operations Management, 23(11), pp1950-1965.

Bhattacharya, S., Hasija, S., \& Wassenhove, L. N. 2014. Designing efficient infrastructural investment and asset transfer mechanisms in humanitarian supply chains. Production and Operations Management, 23(9), pp1511-1521.

Bhattarai, R. K. 2015: Infrastructure development in developing countries: Issues of tourism, cultural configuration, and services alignment. In N. Ray, D. K. Das, S. Chaudhuri, \& A. Ghosh (Eds.), Strategic infrastructure development for economic growth adn social change (pp. 92-119). Hershey: IGI Global.

Bhattarai, R. K. 2016: Empathetic actors strengthen organizational immunity to industrial crisis: Industrial actors' perception in Nepal. Outlines. Critical Practice Studies, 17(1), pp109-128.

Bhimani, S., \& Song, J. S. 2016: Gaps between research and practice in humanitarian logistics. Journal of Applied Business and Economics, 18(1), pp11-24.

Eftekhar, M., Masini, A., Robotis, A., \& Wassenhove, L. N. 2014: Vehicle procurement policy for humanitarian developemnt programs. Production and Operations Management, 23(6), pp951-964.

Galindo, G., \& Batta, R. 2013: Review of recent developments in OR/MS research in disaster operations management. European Journal of Operational Research, 230(2013), pp201-211.

Gatignon, A., Wassenhove, L. N., \& Charles, A. 2010: The Yogyakarta earthquake: Humanitarian relief through IFRC's decentralized supply chain. Int. J. Production Economics, 126(2010), pp102-110.

Green, L. V., \& Kolesar, P. J. 2004: Improving emergency responsiveness with management science. Management Science, 50(8), pp1001-1014.

Holguin-Veras, J., Jaller, M., Wassenhove, L. N., Perez, N., \& Wachtendorf, T. 2012: On the unique features of post-disaster humanitarian logistics. Journal of Operations Management, 30(2012), pp494-506. 
Holguin-Veras, J., Perez, N., Jaller, M., Wassenhove, L. N., \& Aros-Vera, F. 2013: On the appropriate objective function for post-disaster humanitarian logistics models. Journal of Operations Management, 31(2013), pp262-280.

Kilci, F., Kara, B. Y., \& Bozkaya, B. 2014: Locating temporary shelter areas after an earthquake: A case for Turkey. European Journal of Operational Research, 243(2015), pp323-332.

Kretschmer, A., Spinler, S., \& Wassenhove, L. N. 2014: A school feeding supply chain framework: Critical factors for sustainable program design. Production and Operations Management, 23(6), pp990-1001.

Martinez, A. J., Stapleton, O., \& Wassenhove, L. N. 2011: Field vehicle fleed management in humanirarian operations: A case-based approach. Journal of Operations Management, 29(2011), pp404-421.

Ozdamar, L., \& Ertem, M. A. 2014: Models, solutions and enabling technologies in humanitarian logistics. European Journal of Operational Research, 244(2015), pp5565.

Pedraza-Martinez, A. J., \& Wassenhove, L. N. 2013: Vehicle replacement in the International Committee of the Red Cross. Production and Operations Management, 22(2), pp365376.

Sodhi, M. S., \& Tang, C. S. 2014: Buttressing supply chains against floods in Asia for humanitrian relief and economic recovery. Production and Operations Management, 23(6), pp938-950.

Sodhi, M. S., \& Tang, C. S. 2014: Supply-chain research opportunities with the poor as suppliers or distributors in developing countries. Production and Operations Management, 23(9), pp1483-1494.

Tatham, P., \& Kocacs, G. 2009: The application of "swift trust" to humanitarian logistics. Int. J. Production Economics, 126(2010), pp35-45.

UNOCHA. 2005: Cluster coordination. Retrieved May 6, 2016, from United Nations Office for the Coordination of Humanitarian Affairs: http://www.unocha.org/what-we-do/ coordination-tools/cluster-coordination

Vanajakumari, M., Kumar, S., \& Gupta, S. 2016: An integrated logistic model for predictable disasters. Production and Operations Management, 25(5), 791-811.

Wassenhove, L. N., \& Martinez, A. J. 2012: Using OR to adapt supply chain management best practices to humanitarian logistics. International Transactions in Operational Research, 19(2012), pp307-322. 